\title{
Cucurbitacin B and SCH772984 exhibit synergistic anti-pancreatic cancer activities by suppressing EGFR, PI3K/Akt/mTOR, STAT3 and ERK signaling
}

\author{
Jingkai Zhou ${ }^{1}$, Tiangang Zhao' ${ }^{2}$, Linfeng Ma², Min Liang2, Ying-Jie Guo ${ }^{2}$ and Li-Mei \\ Zhao $^{1}$ \\ 'Department of Pharmacy, Shengjing Hospital of China Medical University, Shenyang, China \\ ${ }^{2}$ School of Life Sciences, Jilin University, Changchun, China \\ Correspondence to: Ying-Jie Guo, email: guoyingjie@jlu.edu.cn \\ Li-Mei Zhao, email: zhaolm@sj-hospital.org
}

Keywords: cucurbitacin B, SCH772984, pancreatic cancer, EGFR, ERK

Received: June 29, $2017 \quad$ Accepted: September 21, $2017 \quad$ Published: October 09, 2017

Copyright: Zhou et al. This is an open-access article distributed under the terms of the Creative Commons Attribution License 3.0 (CC BY 3.0), which permits unrestricted use, distribution, and reproduction in any medium, provided the original author and source are credited.

\section{ABSTRACT}

Cucurbitacin B (CuB) is a natural tetracyclic triterpene product and displays antitumor activity across a wide array of cancers. In this study, we explored the antipancreatic cancer activity of CuB alone and in combination with SCH772984, an ERK inhibitor, in vitro and in vivo. CuB inhibited proliferation of pancreatic cancer cells by arresting them in the $\mathrm{G} 2 / \mathrm{M}$ cell cycle phase. This was associated with inhibition of EGFR expression and activity and downstream signaling, including PI3K/Akt/mTOR and STAT3. Interestingly, ERK activity was markedly enhanced by activating AMPK signaling after $12 \mathrm{~h}$ of CuB treatment. SCH772984 potentiates the cytotoxic effect of CuB on pancreatic cancer cells through complementary inhibition of EGFR, PI3K/ Akt/mTOR, STAT3 and ERK signaling, followed by an increase in the pro-apoptotic protein Bim and a decrease in the anti-apoptotic proteins $\mathrm{Mcl}-1, \mathrm{Bcl}-2, \mathrm{Bcl}-\mathrm{xl}$ and survivin. Furthermore, combined therapy with CuB and SCH772984 resulted in highly significant growth inhibition of pancreatic cancer xenografts. These results may provide a basis for further development of combining CUB and ERK inhibitors to treat pancreatic cancer.

\section{INTRODUCTION}

Pancreatic cancer is the fourth most common cause of cancer deaths in Western societies, and fewer than $5 \%$ of newly diagnosed patients survive more than 5 years [1]. The low survival rate is primarily due to the insensitivity of pancreatic cancer to most chemotherapy and radiotherapy treatments $[1,2]$. Therefore, there is an urgent need to develop new agents or combination therapeutic strategies to treat this deadly disease.

Epidermal growth factor receptor (EGFR) plays an important role in pancreatic cancer progression [3]. EGFR is a member of the erb-B receptor tyrosine kinase (TK) family. The activated receptor can induce several downstream signaling pathways, including Ras/Raf/ mitogen-activated extracellular signal-regulated kinase/ extracellular signal-regulated kinase (Ras/Raf/MEK/ ERK), phosphatidylinositol 3-kinase/viral Akt homologue/ mammalian target of rapamycin (PI3K/Akt/mTOR), and signal transducer and activator of transcription 3 (STAT3). These pathways effectively promote cell proliferation, invasion and metastasis by modulating expression of both pro- and anti-apoptotic genes, such as the Bcl-2 family of proteins or survivin $[4,5]$. EGFR overexpression has been observed in $30 \%-89 \%$ of pancreatic cancers $[6,7]$ and is associated with advanced disease, poor survival and metastasis [8]. Thus, EGFR has been considered a potential target for treating pancreatic cancer. However, due to a high rate of acquired or inherent resistance, EGFR inhibitors are insufficient in effectively treating human pancreatic cancer [9]. The most well defined mechanisms of resistance are involved in EGFR-independent 
constitutive activation of downstream effectors, such as mitogen-activated protein kinases (MAPK) [10], PI3K [11] and STAT3 [11], or complex crosstalk among EGFR downstream signaling pathways [12, 13]. Preclinical studies evaluating combination therapy with EGFR and RAS pathway inhibitors in pancreatic cancer have shown promising results [14-16]. Therefore, blocking EGFR and its downstream signaling targets might be a rational strategy for pancreatic cancer therapy.

Cucurbitacins are natural tetracyclic triterpene compounds derived from plants in the Cucurbitaceae family and have a wide spectrum of pharmacological activities, such as anticancer, anti-inflammatory and hepatoprotective effects [17]. Cucurbitacin B is one of the most abundant forms of cucurbitacins and has received increasing attention in recent years for its cytotoxicity across a wide array of cancers, including pancreatic cancer [18-20]. STAT3 is the primary therapeutic target of $\mathrm{CuB}$ in pancreatic cancer. $\mathrm{CuB}$ induces pancreatic cancer cell apoptosis through inhibition of STAT3 signaling [21-26]. Interestingly, accumulated data have demonstrated that $\mathrm{CuB}$ can selectively inhibit other signaling pathways dependent on cancer cell contexts. For example, $\mathrm{CuB}$ suppressed the expression and activity of HER2 as well as EGFR in HER2-overexpressed breast cancer cells [27]. Silva et al. demonstrated that a $\mathrm{CuB}$ derivate had strong cytotoxicity in EGFR-overexpressed non-smallcell lung cancer by interfering with EGFR activation and its downstream effectors, Akt, ERK and STAT3 [28]. Pancreatic cancer is an EGFR-overexpressed solid tumor. Thus, we investigated whether $\mathrm{CuB}$ inhibits pancreatic cancer cell growth by modulating EGFR and its downstream signaling targets and tested whether $\mathrm{CuB}$ in combination with downstream EGFR signaling enhances its therapeutic efficacy.

The results of the present study demonstrate that $\mathrm{CuB}$ treatment alone had strong growth inhibitory effects in pancreatic cancer cells through inhibition of EGFR expression level and activity. Interestingly, the PI3K/ Akt/mTOR pathway and STAT3 activity were potently downregulated after $6 \mathrm{~h}$ of $\mathrm{CuB}$ treatment, whereas ERK activity was markedly upregulated after $12 \mathrm{~h}$ of $\mathrm{CuB}$ treatment by enhancing AMPK activity. Because ERK plays crucial roles in tumorigenesis, cell proliferation and inhibition of apoptosis [29], we infer that reactivation of ERK may be a potent mechanism for resistance to $\mathrm{CuB}$ efficacy and hypothesize that direct inhibition of ERK activation may overcome this limitation. SCH772984, a selective inhibitor of ERK1/2 that has been shown to act as type I and type II kinase inhibitors and inhibit tumor proliferation in mouse pancreatic cancer and breast cancer xenograft models $[30,31]$, was selected to evaluate its effect on CuB-induced cytotoxicity. Synergistic antitumor interactions between CuB and SCH772984 were observed in vitro and in vivo.

\section{RESULTS}

\section{$\mathrm{CuB}$ inhibits proliferation of pancreatic cancer cells}

Considering pancreatic cancer cell heterogeneity, we tested the ability of $\mathrm{CuB}$ to inhibit proliferation in 5 pancreatic cancer cell lines (BxPC-3, MiaPaCa-2, HPAC, CFPAC and ASPC-1) via the MTT assay. A normal pancreatic ductal epithelial cell line (HPDE6-C7) was used as a control. Because $\mathrm{CuB}$ is dissolved in less than $1 \%$. DMSO in cell culture medium, we first observed the effect of DMSO on cell proliferation. MTT analysis revealed that different concentrations of DMSO ranging from 1/300,000 to $1 / 1,000$ did not significantly inhibit proliferation in all cell lines evaluated (Supplementary Figure 1). Interestingly, $\mathrm{CuB}$ potently inhibited proliferation in all pancreatic cancer cell lines in dose- and time-dependent manners (Figure 1). $\mathrm{IC}_{50}$ values varied, ranging from $0.017 \mu \mathrm{M}$ (AsPC-1) to $0.278 \mu \mathrm{M}$ (MiaPaCa-2) after $72 \mathrm{~h}$ of treatment. $\mathrm{CuB}$ did not have a significant effect on normal pancreatic ductal epithelial cell proliferation after $72 \mathrm{~h}$ of treatment (Figure 1). This indicates that $\mathrm{CuB}$ has stronger growth inhibitory effects on pancreatic cancer cells compared to normal pancreatic ductal epithelial cells after $72 \mathrm{~h}$ of treatment.

\section{CuB leads to cell cycle arrest and cell death}

To explore the growth inhibitory mechansims of $\mathrm{CuB}$, we treated 2 pancreatic cancer cell lines that have different Ras and p53 phenotypes [BxPC-3 (Ras wildtype, p53 mutation) and HPAC (Ras mutation, p53 wildtype)] with varying concentrations of $\mathrm{CuB}$ for $24 \mathrm{~h}$. Cell cycle distribution was observed by PI staining followed by flow cytometry. $\mathrm{CuB}$ induced cell accumulation in the $\mathrm{G} 2 / \mathrm{M}$ phase in a dose-dependent manner, accompanied by a decrease in the G0/G1 phase fraction (Figure 2A2D). We also observed expression of $\mathrm{G} 2 / \mathrm{M}$ phase-related proteins by Western blotting analysis. CuB treatment resulted in an increase in Tyr15 phosphorylated CDK1 in BxPC-3 and HPAC cells (Figure 2E). Cyclin B1 protein levels remained unchanged in BxPC-3 cells, but were decreased in HPAC cells (Figure 2E). This indicates that $\mathrm{CuB}$ inhibits pancreatic cancer cell growth by arresting cells in the G2/M cell cycle phase.

Another mechanism of cell growth inhibition is to cause cell death. Trypan blue exclusion analysis showed that less than $15 \%$ of cells were observed to be dead at the highest concentration of $0.9 \mu \mathrm{M}$ in both cell types (Figure $2 \mathrm{~F}$ ), indicating that $\mathrm{CuB}$ alone has a limited ability to cause cell death, which was further demonstrated by LDH release assay (Figure 2G). A low number of cells with DNA fragments (Sub-G1) was also observed after CuB $24 \mathrm{~h}$ treatment (Figure $2 \mathrm{H}$ ), accompanied by an increase in cleaved PARP (Figure 2I). 


\section{CuB suppresses EGFR and downstream PI3K/ Akt/mTOR and STAT3 signaling}

We examined the association between the growth inhibitory effect of $\mathrm{CuB}$ and EGFR signaling in BxPC3 and HPAC cells. CuB effectively inhibited EGFR and pEGFR levels in both cell types in a dose-dependent manner (Figure $3 \mathrm{~A}$ ). $\mathrm{CuB}$ also reduced the levels of the EGFR downstream effectors pAkt (T308), pAkt (S473), pS6 and pSTAT3 without altering total protein levels of Akt and STAT3 in BxPC-3 cells (Figure 3A). Similar results were also observed in HPAC cells, except for decreased Akt levels (Figure 3A). We then used $0.3 \mu \mathrm{M} \mathrm{CuB}$ to determine the effects over time. In both cell lines, decreased EGFR, pEGFR, pAkt (T308), pAkt (S473), pS6 and pSTAT3 levels were detected as early as $6 \mathrm{~h}$ and remained low levels throughout the $24 \mathrm{~h}$ time period (Figure 3B). This indicates that EGFR, PI3K/Akt/mTOR and STAT3 signaling are simultaneously inhibited after $6 \mathrm{~h}$ of $\mathrm{CuB}$ treatment.

To provide further evidence that decreased EGFR levels are required for $\mathrm{CuB}$-induced growth inhibition in pancreatic cancer cells, we performed lentiviral shRNA knockdown of EGFR in BxPC-3 and HPAC cells (EGFRshRNA), which was compared to non-target control cells (NTC-shRNA) by Western blotting analysis (Figure 3E). Cell proliferation in the absence or presence of $\mathrm{CuB}$ was then determined by the MTT assay. EGFR-shRNA cells had a slower growth rate than NTC-shRNA cells in the absence of $\mathrm{CuB}$ (Figure $3 \mathrm{C}$ and $3 \mathrm{D}$ ). $\mathrm{CuB}$ significantly inhibited the growth of EGFR-shRNA HPAC cells at all concentrations evaluated compared to NTC-shRNA HPAC cells, whereas the growth of EGFR-shRNA BxPC-3 cells was significantly inhibited compared to NTC-shRNA BxPC- 3 cells at low $\mathrm{CuB}$ concentrations (Figure $3 \mathrm{C}$ and 3D). We also observed decreased protein levels of the EGFR downstream effectors pAkt (T308), pAkt (S473), pS6, pSTAT3 and pERK in EGFR-shRNA cells compared to NTC-shRNA cells without changes in total protein levels (Figure 3E). This suggests that downregulation of EGFR protein levels is responsible for the growth inhibitory effect of $\mathrm{CuB}$ in pancreatic cancer cells.

\section{CuB enhances ERK activity by activating AMPK signaling}

Since the MEK/ERK pathway is also an important downstream component of EGFR signaling, we next observed the effect of $\mathrm{CuB}$ on ERK activity. There was a dose-dependent stimulatory effect on ERK activity after $24 \mathrm{~h}$ of $\mathrm{CuB}$ treatment in BxPC-3 and HPAC cells, as monitored by ERK phosphorylation (Figure 4A). Time course experiments revealed a dynamic change in pERK levels during $24 \mathrm{~h}$ of $\mathrm{CuB}$ treatment in both cell lines. Upon $\mathrm{CuB}$ treatment, pERK levels were decreased at $6 \mathrm{~h}$, then increased after $12 \mathrm{~h}$ relative to the corresponding vehicle control treatment (Figure 4B).
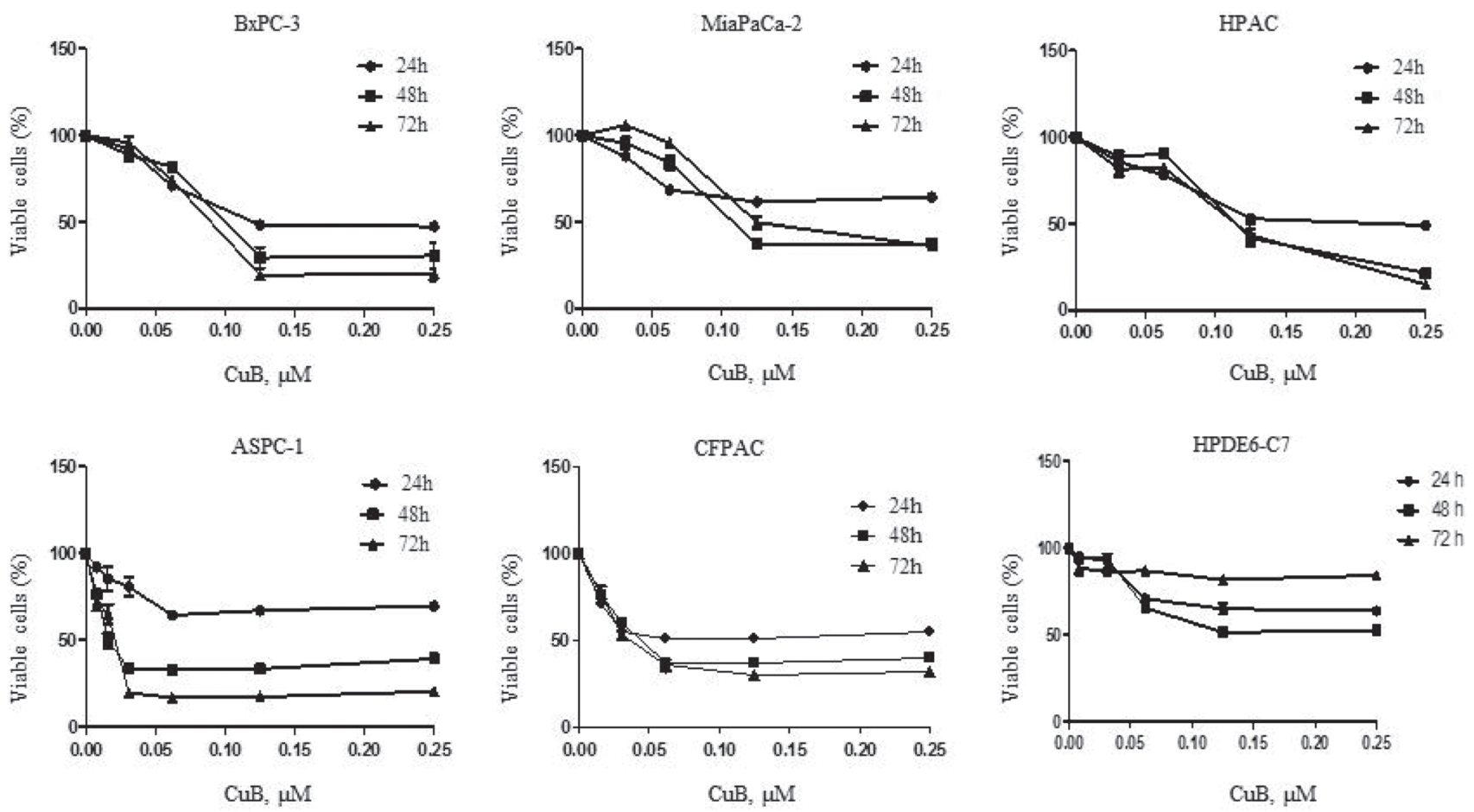

Figure 1: CuB inhibits proliferation of pancreatic cancer cells. BxPC-3, MiaPaCa-2, HPAC, ASPC-1, CFPAC and HPDE6-C7 cells were cultured with $\mathrm{CuB}$ for 24, 48, and 72 hours. Viable cells were determined with the MTT assay. Data are presented as the mean \pm standard error from at least 3 independent experiments. 

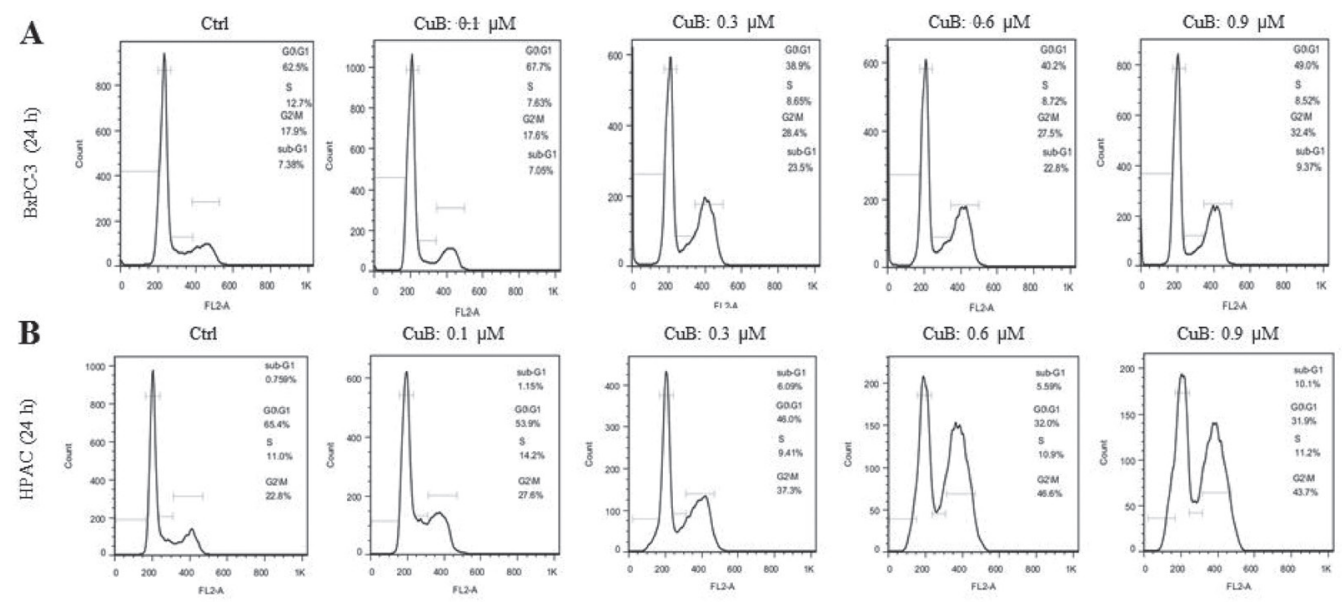

C

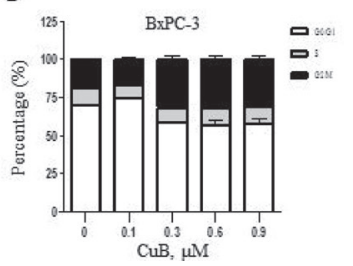

D
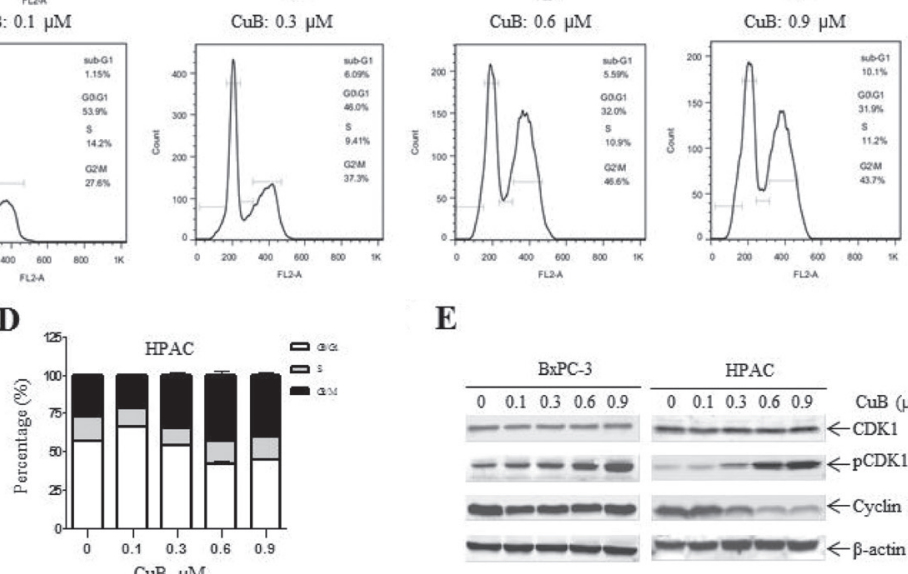

$\mathbf{E}$
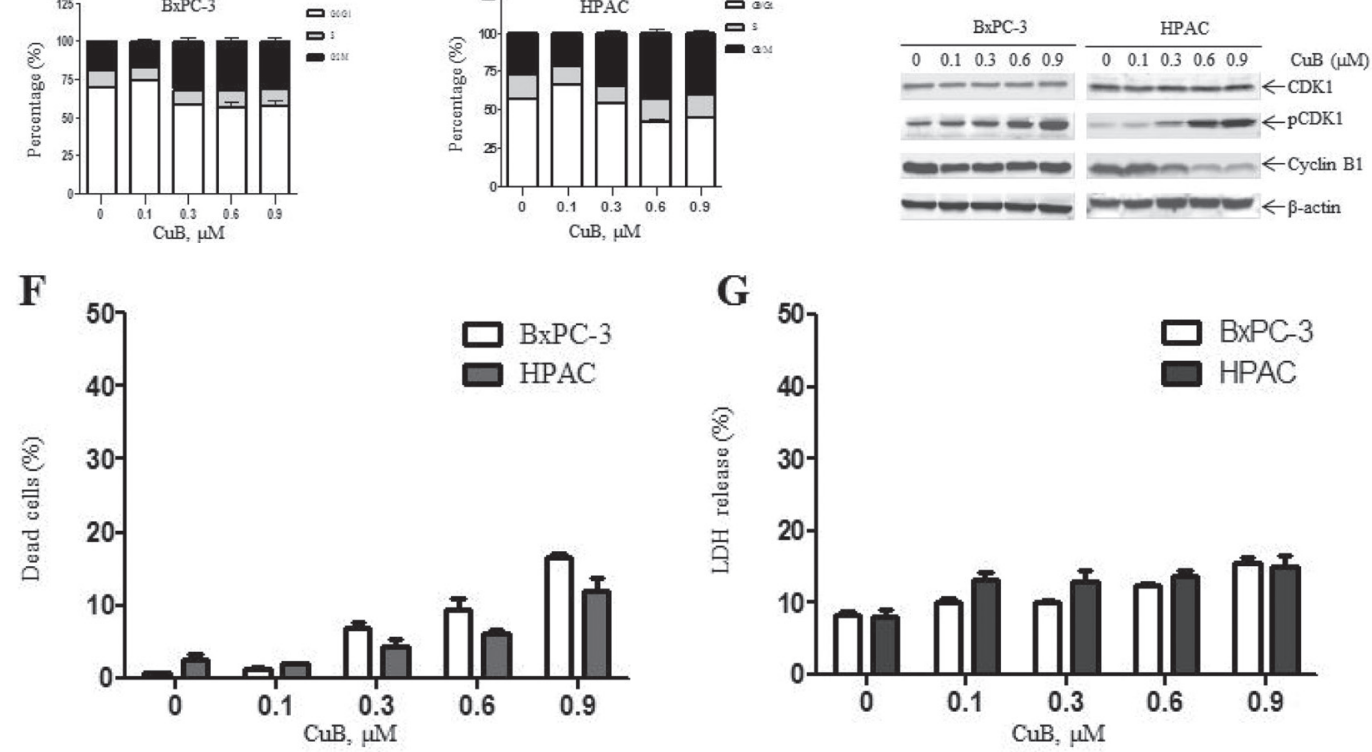

H

I
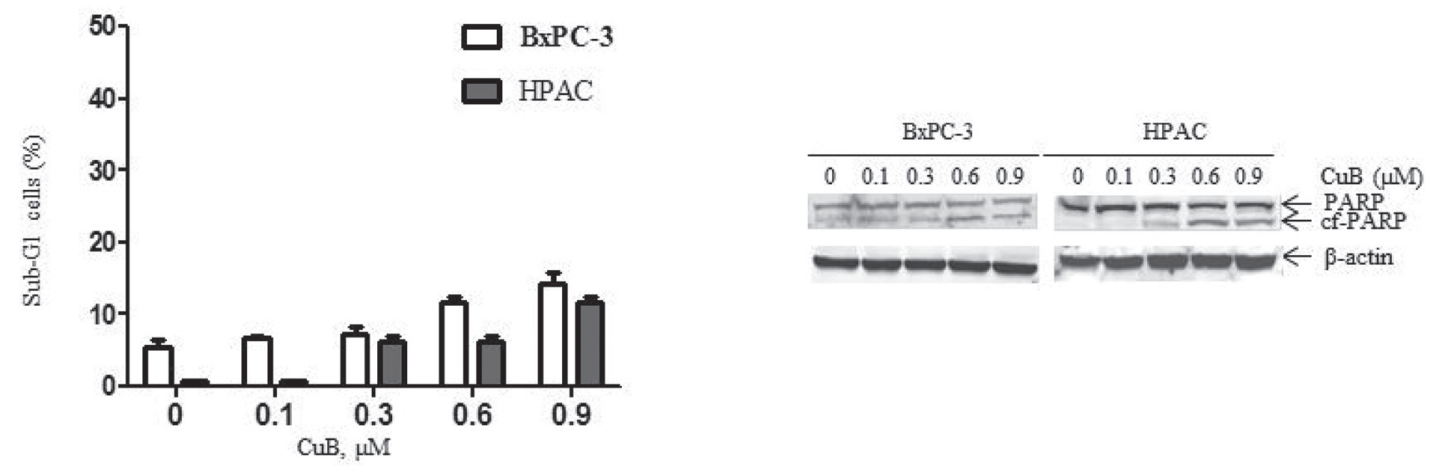

Figure 2: CuB leads to cell cycle arrest and cell death. (A and B) BxPC-3 and HPAC cells were treated with vehicle control or varying concentrations of $\mathrm{CuB}$ for $24 \mathrm{~h}$, fixed with $80 \%$ ice-cold ethanol, and stained with PI for cell cycle analysis. Representative histograms are shown. (C and D) Histograms represent the relative distribution of non-apoptotic cells between the G0/G1, S, and G2/M phases. (E) Whole cell lysates were analyzed by Western blotting and probed with anti-CDK1, -pCDK1, -Cyclin B1, or - $\beta$-actin antibodies. (F) BxPC-3 and HPAC cells were treated with vehicle control or different $\mathrm{CuB}$ concentrations for $24 \mathrm{~h}$, then stained with trypan blue. Histograms represent the percentage of dead cells. (G) BxPC-3 and HPAC cells were treated with vehicle control or different CuB concentrations for $24 \mathrm{~h}$. Culture medium was collected and LDH release was assessed. Histograms represent the percentage of LDH release. (H) Sub-G1 data are presented as the mean of triplicate data \pm SEM from one representative experiment. (I) BxPC-3 and HPAC cells were treated with vehicle control or different $\mathrm{CuB}$ concentrations for $24 \mathrm{~h}$. Whole cell lysates were analyzed by Western blotting and probed with anti-PARP or - $\beta$-actin antibodies. Experiments were performed at least 3 independent times, and representative Western blots are shown. 
We observed decreased pERK levels in EGFRshRNA cells relative to NTC-shRNA control cells (Figure $3 \mathrm{G}$ ), suggesting that enhanced pERK levels may be independent of EGFR downregulation by $\mathrm{CuB}$. Given that potential cross-talk between AMPK and ERK signaling has been reported [32-34], we examined phosphorylated and total protein levels of AMPK $\alpha$ after $24 \mathrm{~h}$ of $\mathrm{CuB}$ treatment. $\mathrm{CuB}$ effectively enhanced pAMPK $\alpha$ levels in both cell lines in a dose-dependent manner without altering total AMPK $\alpha$ protein levels (Figure 4A). Importantly, time course experiments also showed decreased pAMPK $\alpha$ levels at $6 \mathrm{~h}$ and increased pAMPK $\alpha$ levels after $12 \mathrm{~h}$ relative to the corresponding vehicle control treatment (Figure 4B). Phosphorylated levels of AMPK $\alpha$ and ERK showed corresponding changes over time in both cell lines. We observed the effects of compound $\mathrm{C}$, a selective AMPK inhibitor, on pERK levels using Western blotting analysis. Compound $\mathrm{C}$ significantly inhibited an increase in pERK levels by $\mathrm{CuB}$ in both cell lines (Figure 4C), suggesting that $\mathrm{CuB}$ may increase $\mathrm{pERK}$ protein levels by activating AMPK. Because AMPK negatively regulates the mTOR signaling pathway, we also observed pS6 levels in the presence of $\mathrm{CuB}$ and compound C. Decreased pS6 levels due to $\mathrm{CuB}$ were restored to some extent after the combined treatment (Figure 4C). Consistently, AMPK $\alpha$ CRISPR knockdown reversed the increase in pERK and decrease in pS6 levels due to $\mathrm{CuB}$ in BxPC-3 and HPAC cells (Figure 4D). These results demonstrate that AMPK activation plays an important role in CuB-induced ERK phosphorylation and pS6 downregulation.

\section{SCH772984 synergizes with $\mathrm{CuB}$ to induce growth inhibition and apoptosis of pancreatic cancer cells}

To explore the effect of ERK over-activation on CuB-induced cytotoxicity, cell proliferation was measured after $24 \mathrm{~h}$ or $48 \mathrm{~h}$ of treatment with $\mathrm{CuB}$ and SCH772984
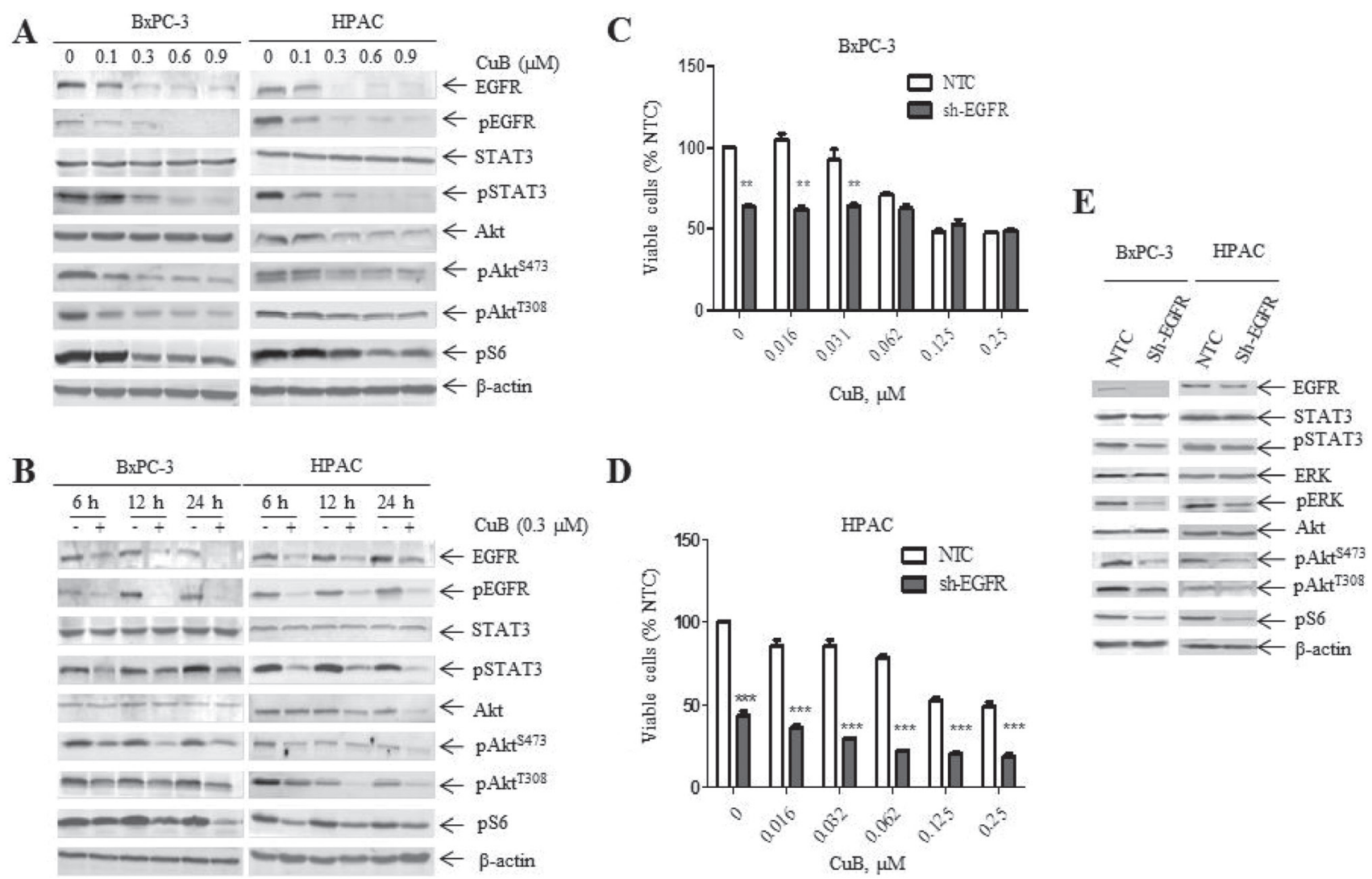

Figure 3: CuB suppresses EGFR levels and downstream PI3K/Akt/mTOR and STAT3 signaling. (A) BxPC-3 and HPAC cells were treated with vehicle control or $\mathrm{CuB}$ for $24 \mathrm{~h}$. Whole cell lysates were analyzed by Western blotting and probed with the indicated antibodies. (B) BxPC-3 and HPAC cells were treated with $0.3 \mu \mathrm{M} \mathrm{CuB}$ for up to $24 \mathrm{~h}$. Cells were harvested and lysed. Protein extracts were analyzed by Western blotting and probed with the indicated antibodies. (C and D) BxPC-3 and HPAC cells were infected with EGFR (EGFR-shRNA) or non-target control shRNA lentivirus (NTC-shRNA). EGFR-shRNA or NTC-shRNA groups were cultured with CuB for $24 \mathrm{~h}$. Cell viability was determined daily using the MTT assay. Data are presented as the mean \pm standard error from at least 3 independent experiments. Statistical significance was calculated using the pair-wise 2 -sample $t$-test. ${ }^{* * *}$ indicates $p<0.001,{ }^{* *} p<0.01$. (E) NTC- and EGFR-shRNA whole cell lysates were analyzed by Western blotting and probed with the indicated antibodies. Experiments were performed at least 3 independent times, and representative Western blots are shown. 
alone or in combination using the MTT assay. When administered simultaneously, SCH772984 significantly enhanced sensitivity to $\mathrm{CuB}$, which is reflected by decreased $\mathrm{IC}_{50}$ values in 5 pancreatic cancer cell lines (Figure 5A and Table 1). Combined effects of $\mathrm{CuB}$ with SCH772984 on growth of the 5 pancreatic cancer cells were clearly synergistic, as shown by all points below the line using standard isobologram analysis and all CIs (combination indices) $<1.00$ (Figure 5A and Table 1). In contrast, combined effects of $\mathrm{CuB}$ with SCH772984 on normal pancreatic ductal epithelial cell proliferation were antagonistic, shown as all points above the line using standard isobologram analysis and all CIs $>1.00$. These data indicate that $\mathrm{SCH} 772984$ significantly enhanced $\mathrm{CuB}$ sensitivity in pancreatic cancer cells, but not in normal pancreatic ductal epithelial cells.

We next investigated whether $\mathrm{CuB}$ and SCH772984 could cooperate to induce cell death. Annexin V/PI double staining and flow cytometry analyses showed that combination treatment significantly increased cell apoptosis relative to individual treatment in BxPC-3 and HPAC cells (Figure 5B), which was accompanied

A

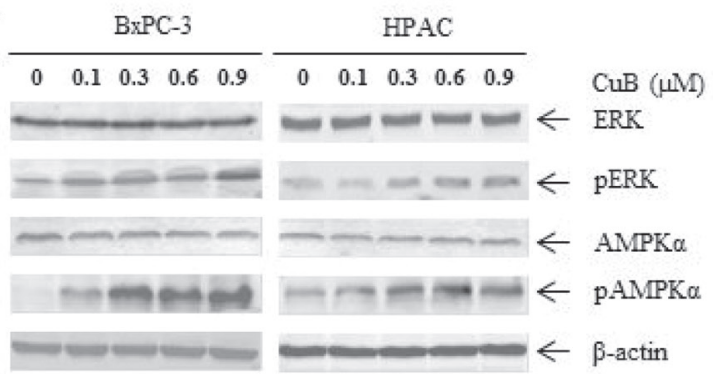

C

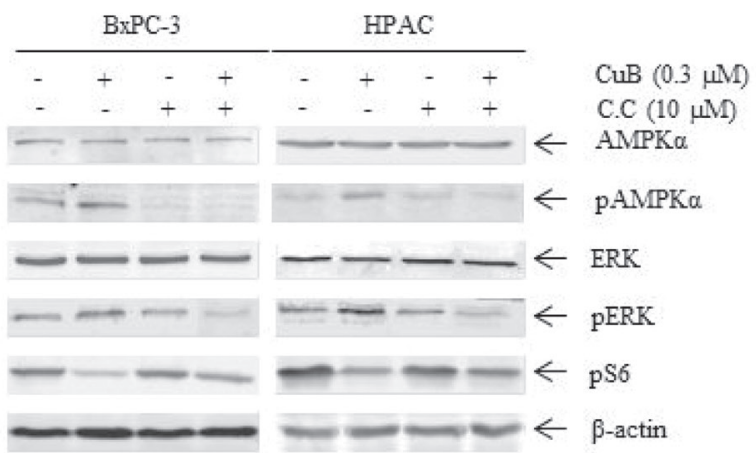

by increased PARP and caspase- 3 cleavage (Figure 5C). These results demonstrate that $\mathrm{CuB}$ and $\mathrm{SCH} 772984$ synergistically promote pancreatic cancer cell apoptosis.

\section{$\mathrm{CuB}$ in combination with $\mathrm{SCH} 772984$ inhibits EGFR and downstream signaling}

We observed the effects of $\mathrm{CuB}$ in combination with SCH772984 on EGFR and downstream signaling. $\mathrm{SCH} 772984$ at $2 \mu \mathrm{M}$ abrogated both ERK protein levels and ERK phosphorylation, which is in accordance with its effect as an ERK inhibitor. As expected, CuB-activated ERK phosphorylation was markedly suppressed by combination treatment with SCH772984 and CuB (Figure 6A). In addition, EGFR, pEGFR, pAkt (T308), pAkt (S473), pS6 and pSTAT3 levels were lower after the combined treatment than after vehicle control treatment in BxPC-3 and HPAC cells (Figure 6A). We also investigated the effects of SCH772984 and CuB, either alone or in combination, on Bcl-2 family proteins and survivin in both cell types. Mcl-1 protein levels were much lower after the combined treatment than after $\mathrm{CuB}$ or $\mathrm{SCH} 772984$

B

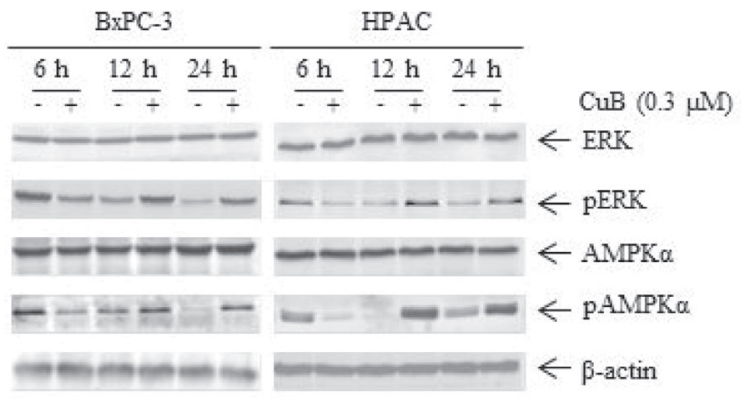

D

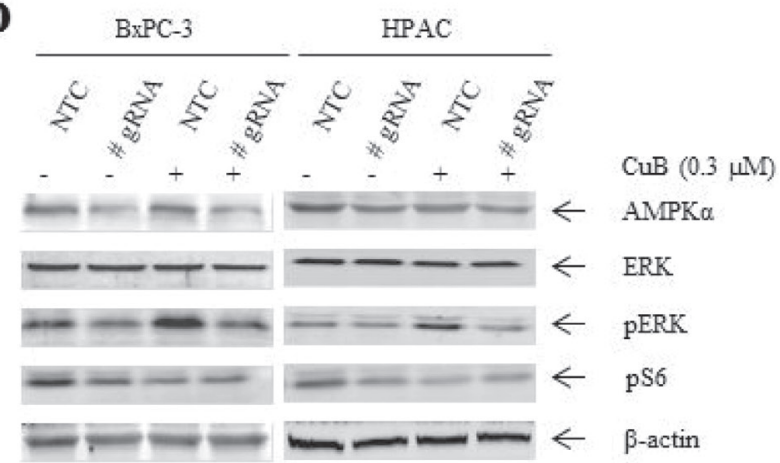

Figure 4: CuB enhances ERK activity via AMPK activation. (A) BxPC-3 and HPAC cells were treated with vehicle control or $\mathrm{CuB}$ for $24 \mathrm{~h}$. Whole cell lysates were analyzed by Western blotting and probed with anti-AMPK $\alpha$, -pAMPK $\alpha$, -ERK, -pERK or $-\beta$-actin antibodies. (B) BxPC-3 and HPAC cells were treated with $0.3 \mu \mathrm{M} \mathrm{CuB}$ for up to $24 \mathrm{~h}$. Cells were harvested and lysed. Protein extracts were analyzed by Western blotting and probed with the indicated antibodies. (C) BxPC-3 and HPAC cells were treated with CuB and compound C (C.C) alone or in combination for $24 \mathrm{~h}$. Whole cell lysates were analyzed by Western blotting and probed with anti-AMPKa, -pAMPKa, -ERK, -pERK, -pS6 or - $\beta$-actin antibodies. (D) BxPC-3 and HPAC cells were infected with non-template control (NTC) or AMPK $\alpha$ CRISPR lentivirus (\#gRNA). Cells were then treated with or without CuB for $24 \mathrm{~h}$. Whole cell lysates were analyzed by Western blotting and probed with the indicated antibodies. Experiments were performed at least 3 independent times, and representative Western blots are shown. 
treatment alone. The combined treatment also resulted in an increase in Bim levels and a decrease in Bcl-2, Bcl-xl and survivin compared to vehicle control (Figure 6B).

\section{Antitumor efficacy of $\mathrm{CuB}$ and SCH772984 in vivo}

We used a mouse HPAC xenograft model to evaluate the effects of $\mathrm{CuB}$ and SCH772984 on pancreatic tumor growth. Individual and combined drug treatments were well tolerated, as indicated by the lack of a significant loss of body weight (Figure 7A). Compared to vehicle control treatment, successive 4-week treatment with $\mathrm{CuB}$ or SCH772984 alone significantly reduced tumor growth, resulting in lower mean tumor volumes $(63.8 \%$ and $54.7 \%$ on day 28 , respectively, Figure $7 \mathrm{~B}$ ). In particular, the combined drug treatment resulted in significant delay of tumor growth during the treatment period compared to single drug treatment, with $85.0 \%$ tumor growth inhibition on day 28 (Figure 7B). Decrease in tumor volume was also verified by a decrease in tumor weight (Figure 7C). $\mathrm{CuB}$ in combination with SCH772984 significantly decreased the average tumor weight relative to $\mathrm{CuB}$ or SCH772984 alone on day 28.

To further investigate the in vivo effects of $\mathrm{CuB}$ and SCH772984 treatment, tumors were analyzed by HE, immunohistochemical and TUNEL staining. Individual drug treatment resulted in increased tumor necrosis, which was further increased following combination treatment, as indicated in arrows in HE staining (Figure 7D). Proliferation was substantially lower in the combination group compared to the single groups, as indicated by lower PCNA staining (Figure 7E). The combined drug treatment resulted in increased cell apoptosis, as measured by the TUNEL assay (Figure 7F). These data emphasize the potential for using combined $\mathrm{CuB}$ and SCH772984 to treat pancreatic cancer.

\section{DISCUSSION}

Pancreatic cancer is an oncogene-driven tumor with multiple genetic and epigenetic alterations. These genetic alterations may contribute to its aggressive nature and confer resistance to conventional and targeted agents [35, 36]. EGFR overexpression has been observed in most pancreatic cancer patients $[6,8]$ and plays prominent roles in malignant transformation, prevention of apoptosis, and drug resistance [3]. Due to a high rate of acquired or inherent resistance, targeting EGFR has proven to be insufficient in effectively treating human pancreatic cancer [9]. In addition, targeting one downstream pathway usually leads to compensatory activation of interconnected survival pathways. In this study, we demonstrate for the first time that $\mathrm{CuB}$ inhibits pancreatic cancer cell proliferation by interfering with EGFR levels and downstream signaling of PI3K/Akt/
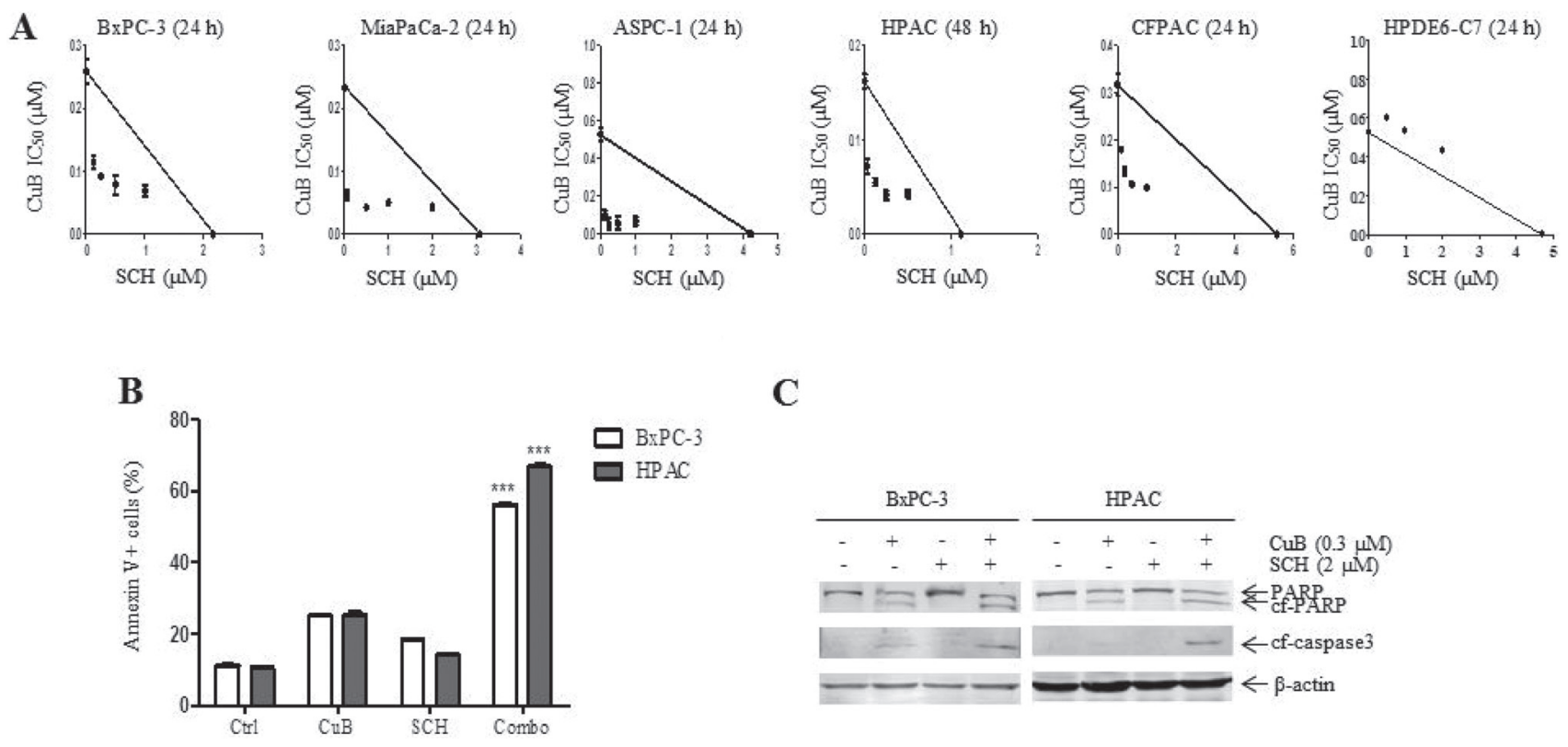

C

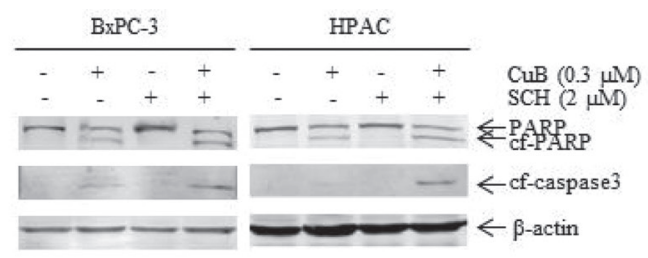

Figure 5: SCH772984 synergizes with CuB to induce growth inhibition and apoptosis of pancreatic cancer cells. (A) Standard isobologram analyses of antitumor interactions between SCH772984 and CuB in pancreatic cancer cells were performed. (B) BxPC-3 and HPAC cells were treated with vehicle control, CuB $(0.3 \mu \mathrm{M})$, SCH772984 $(2 \mu \mathrm{M})$ or CuB plus SCH772984 for 24 h. Cell death was determined by annexin V/PI staining and flow cytometry analyses. Dead cells are expressed as the percentage of annexin V+ cells. Data are presented as the mean of triplicate experiments \pm standard error from 1 representative experiment. Statistical significance was calculated using the pair-wise 2 -sample $t$-test. ${ }^{* * *}$ indicates $p<0.001$. (C) Protein extracts were analyzed by Western blotting and probed with anti-PARP, -cf-caspase 3 or $-\beta$-actin antibodies. 
Table 1: Effects of SCH772984 on CuB sensitivities in pancreatic cell lines

\begin{tabular}{|c|c|c|c|c|c|c|}
\hline \multirow[t]{2}{*}{ Cell lines } & \multirow{2}{*}{$\begin{array}{l}\text { IC50 of SCH772984 } \\
(\mu \mathrm{M})\end{array}$} & \multicolumn{4}{|c|}{$\begin{array}{c}\text { IC50 of CuB }(\mu \mathrm{M}) \text { in the absence or presence of } \\
\mathrm{SCH772984}(\mu \mathrm{M})\end{array}$} & \multirow[t]{2}{*}{$P$ Value } \\
\hline & & $\mathbf{0}$ & 0.5 & 1 & 2 & \\
\hline ВxPC-3 & $2.41 \pm 0.78$ & $0.20 \pm 0.01$ & $\begin{array}{l}0.11 \pm 0.04 \\
(0.66)\end{array}$ & $\begin{array}{l}0.09 \pm 0.03 \\
(0.71)\end{array}$ & $\begin{array}{l}0.07 \pm 0.02 \\
(0.67)\end{array}$ & $<0.05$ \\
\hline ASPC-1 & $4.23 \pm 0.66$ & $0.14 \pm 0.06$ & $\begin{array}{l}0.11 \pm 0.09 \\
(0.08)\end{array}$ & $\begin{array}{l}0.12 \pm 0.09 \\
(0.13)\end{array}$ & $\begin{array}{l}0.12 \pm 0.08 \\
(0.13)\end{array}$ & $<0.05$ \\
\hline MiaPaCa-2 & $3.07 \pm 0.34$ & $0.25 \pm 0.02$ & $\begin{array}{l}0.16 \pm 0.02 \\
(0.11)\end{array}$ & $\begin{array}{l}0.17 \pm 0.02 \\
(0.16)\end{array}$ & $\begin{array}{l}0.18 \pm 0.03 \\
(0.16)\end{array}$ & $<0.05$ \\
\hline HPAC & $1.12 \pm 0.16$ & $0.18 \pm 0.05$ & $\begin{array}{l}0.06 \pm 0.01 \\
(0.26)\end{array}$ & $\begin{array}{l}0.04 \pm 0.01 \\
(0.48)\end{array}$ & $\begin{array}{l}0.04 \pm 0.01 \\
(0.21)\end{array}$ & $<0.05$ \\
\hline CFPAC & $5.42 \pm 0.77$ & $0.32 \pm 0.01$ & $\begin{array}{l}0.25 \pm 0.12 \\
(0.32)\end{array}$ & $\begin{array}{l}0.28 \pm 0.13 \\
(0.20)\end{array}$ & $\begin{array}{l}0.23 \pm 0.14 \\
(0.58)\end{array}$ & $<0.05$ \\
\hline HPDE6-C7 & $4.72 \pm 0.86$ & $0.51 \pm 0.04$ & $\begin{array}{l}0.50 \pm 0.26 \\
(>1)\end{array}$ & $\begin{array}{l}0.51 \pm 0.13 \\
(>1)\end{array}$ & $\begin{array}{l}0.48 \pm 0.14 \\
(>1)\end{array}$ & $>0.05$ \\
\hline
\end{tabular}

Note: $\mathrm{CuB}$ and $\mathrm{SCH} 772984 \mathrm{IC}_{50} \mathrm{~s}$ are presented as the mean \pm standard error from at least three independent experiments. Numbers in parentheses represent the combination index values. $P$ values for each pair were determined using GraphPad Prism 5.0.

mTOR and STAT3. CuB enhances ERK activity via activating AMPK signaling (Figure 8). The ERK-selective inhibitor SCH772984 synergistically enhanced CuBinduced cell death in 5 pancreatic cancer cell lines (Figure 8 ). Combined treatment resulted in $85 \%$ tumor growth inhibition on day 28 in a HPAC xenograft mouse model.

In this study, we selected 5 pancreatic cancer cell lines with different genetic backgrounds to observe the effects of $\mathrm{CuB}$ on cell growth. $\mathrm{CuB}$ inhibited pancreatic cancer cell growth with $\mathrm{IC}_{50}$ values between 0.017 $\mu \mathrm{M}$ (ASPC-1) and $0.278 \mu \mathrm{M}(\mathrm{MiaPaCa}-2)$ after $72 \mathrm{~h}$ treatment. This indicates that $\mathrm{CuB}$ has strong growth inhibitory effects in pancreatic cancer cells, with all $\mathrm{IC}_{50}$ values below $1 \mu \mathrm{M}$. Both $\mathrm{MiaPaCa}-2$ (insensitive to $\mathrm{CuB}$ ) and $\mathrm{ASPC}-1$ (sensitive to $\mathrm{CuB}$ ) have Ras and p53 mutations, which occur in $90 \%$ and $50-75 \%$ of pancreatic cancer patients, respectively, and can activate multiple signaling pathways related to cell proliferation and antiapoptosis $[37,38]$. This suggests that $\mathrm{CuB}$-induced growth inhibitory effects are not associated with Ras and p53 mutations in pancreatic cancer cells. It has been reported that $\mathrm{CuB}$ can inhibit pancreatic cancer cell growth by arresting cells in the $\mathrm{G} 2 / \mathrm{M}$ cell cycle phase [21], which is consistent with our results. Another mechanism of cell
A

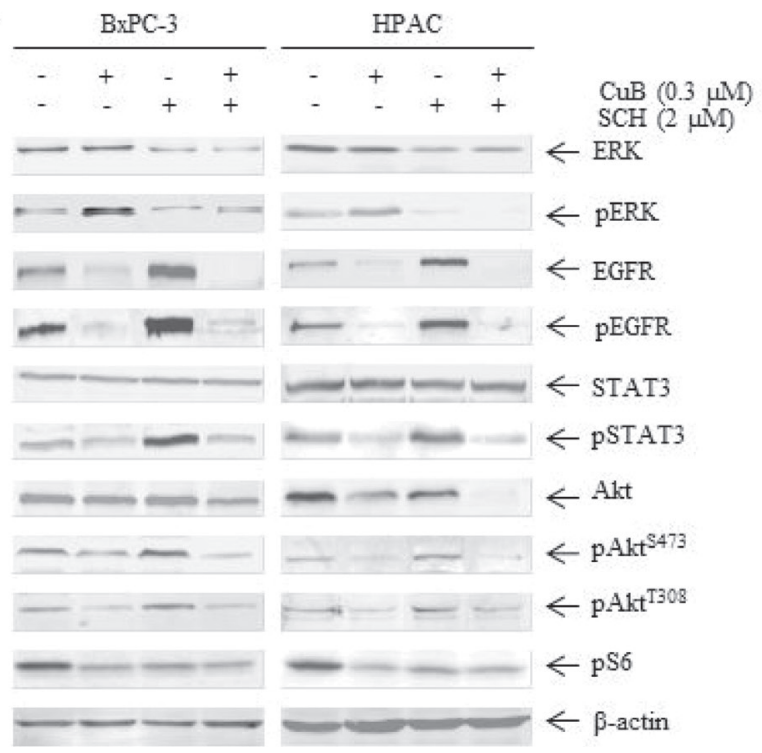

B

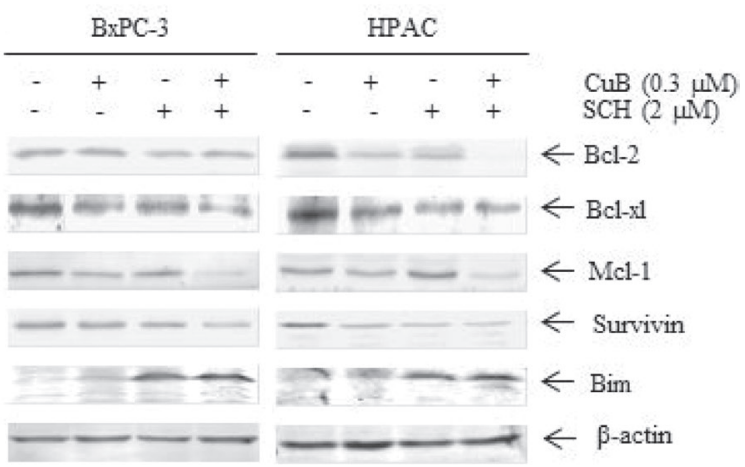

Figure 6: CuB in combination with SCH772984 inhibits EGFR and downstream signaling. (A and B) BxPC-3 and HPAC cells were treated with $\mathrm{CuB}$ and SCH772984 alone or in combination for $24 \mathrm{~h}$. Whole cell lysates were analyzed by Western blotting and probed with the indicated antibodies. 
growth inhibition is to cause cell death. Interestingly, $\mathrm{CuB}$ at the highest concentration of $0.9 \mu \mathrm{M}$ only led to about $15 \%$ cell death after $24 \mathrm{~h}$ of treatment in BxPC-3 and HPAC cells. These findings suggest that growth inhibition mainly contributes to the cytotoxicity of $\mathrm{CuB}$ in pancreatic cancer cells. Interestingly, $72 \mathrm{~h}$ of $\mathrm{CuB}$ treatment had fewer growth inhibitory effects on the 5 pancreatic cancer cell lines evaluated than on HPDE6-C7 cells, indicating that $\mathrm{CuB}$ has low toxicity in normal pancreatic ductal epithelial cells.

Inhibition of the JAK/STAT3 pathway has been classically known as a mechanism of pancreatic cancer cytotoxicity caused by $\mathrm{CuB}$ [22]. Our study demonstrated that $\mathrm{CuB}$ not only decreased pSTAT3 protein levels, but also inhibited endogenous EGFR, pEGFR, pAkt (T308), pAkt (S473) and pS6 levels in a dose-dependent manner in pancreatic cancer cells. This suggests that STAT3 is not a unique therapeutic target in pancreatic cancer cells. In addition to cytokine receptors (e.g., JAKs), STAT3 signaling can also be activated by growth factor receptor tyrosine kinases (e.g., EGFR).
To elucidate an association between decreased EGFR/ pEGFR and pSTAT3, we observed protein levels over time. The results showed that both EGFR/pEGFR and pSTAT3 levels were synchronously decreased as early as $6 \mathrm{~h}$ after $\mathrm{CuB}$ treatment. Further, EGFR knockdown showed that pSTAT3 levels were lower in EGFR-shRNA pancreatic cancer cells compared to NTC-shRNA control cells without altering total protein levels, suggesting that STAT3 phosphorylation is partly dependent on EGFR protein levels. Similar results were also observed in the association between decreased EGFR/pEGFR and decreased pAkt or pS6. These results indirectly demonstrate that $\mathrm{CuB}$ inhibits the activities of STAT3, Akt and S6 in part by downregulating EGFR expression and activity.

Fujita et al. reported that EGFR overexpression was associated with poor prognosis and tumor aggressiveness in pancreatic cancer [39]. Consistent with these findings, we demonstrated that EGFR knockdown inhibited the growth of pancreatic cancer cells. After treatment with $\mathrm{CuB}$, growth of EGFR-shRNA HPAC cells was further
A

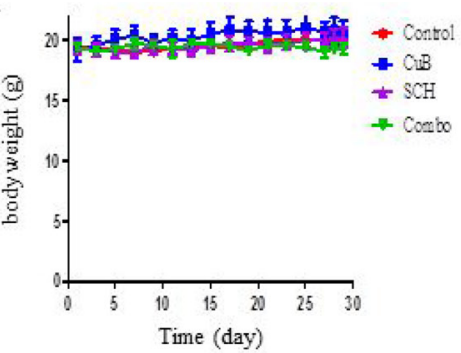

D

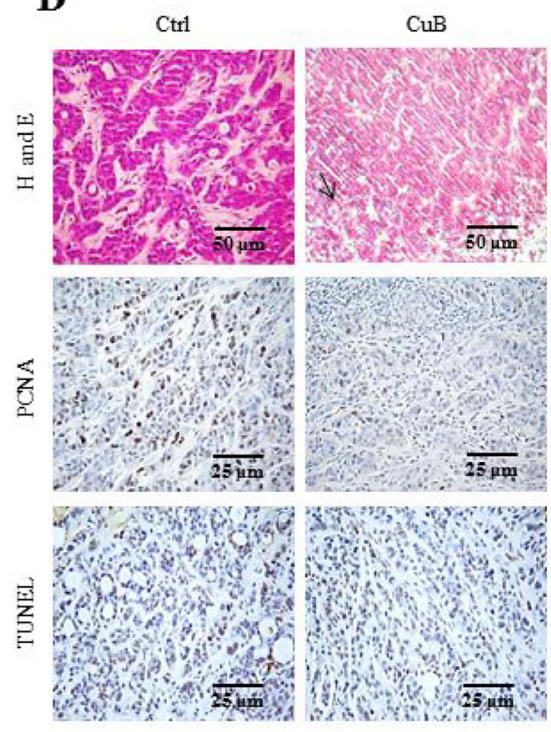

B

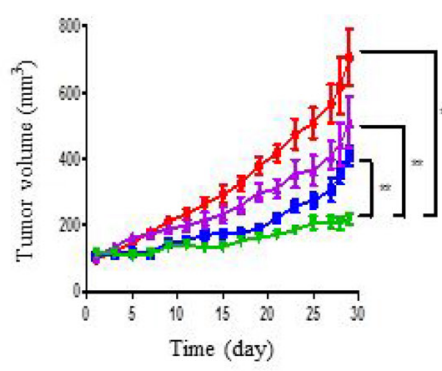

$\mathrm{SCH}$

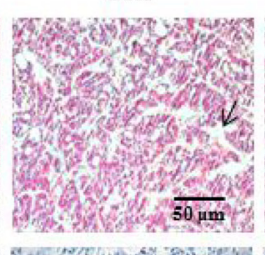

Combo

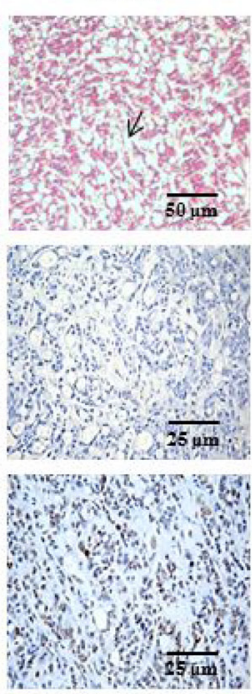

$\mathbf{C}$

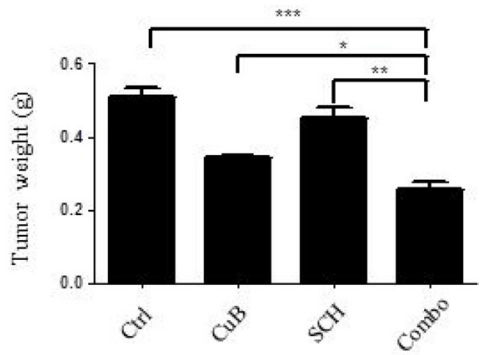

$\mathbf{E}$

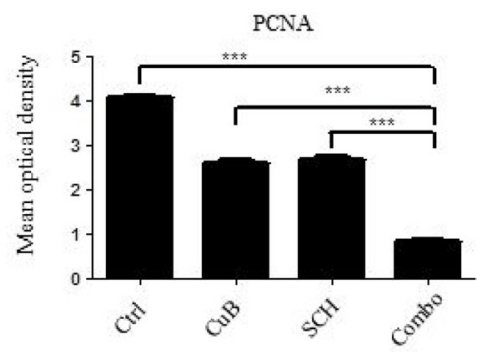

$\mathbf{F}$

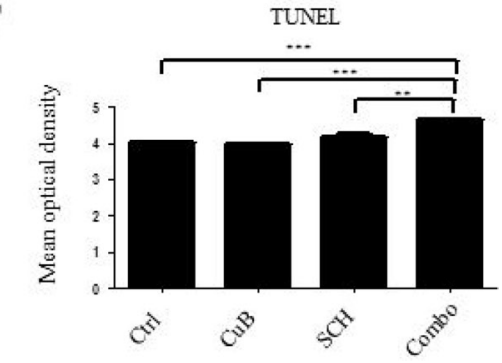

Figure 7: Antitumor efficacy of CuB and SCH772984 in vivo. (A) Body weights were measured daily. (B) Tumor volumes were calculated according to the following formula: $\mathrm{m}_{1}^{2} \times \mathrm{m}_{2} \times 0.5236\left(\mathrm{~m}_{1}\right.$ : short diameter; $\mathrm{m}_{2}$ : long diameter). (C) Overall weight of the dissected tumors. Mean \pm SD of overall tumor weight was measured at autopsy. (D) HE and immunohistochemical staining were evaluated by microscopy at $\times 200$ magnification, scale bar $=50 \mu \mathrm{m}$. (E) Immunohistochemical staining and (F) TUNEL were analyzed with Image Motic Images Advanced 3.2, scale bar $=25 \mu \mathrm{m}$. Graphed as the mean \pm standard error. ${ }^{* * *} p<0.001,{ }^{* *} p<0.01,{ }^{*} p<0.05$. 
inhibited. Interestingly, $\mathrm{CuB}$ had no obvious dosedependency regarding growth inhibitory effects in EGFRshRNA BxPC-3 cells (Figure 3C). This may be attributed to more efficient EGFR knockdown in BxPC-3 cells, as shown in Figure 3E. In addition, we also showed that treatment with $0.062,0.125$ and $0.250 \mu \mathrm{M}$ of $\mathrm{CuB}$ did not result in any differences in cell viability between EGFRshRNA and NTC-shRNA BxPC-3 cells, which may be associated with significant downregulation of EGFR expression after treatment with a high dose of $\mathrm{CuB}$ in BxPC-3 cells. These results suggest that EGFR may be an important target of $\mathrm{CuB}$ in pancreatic cancer therapy.

ERK is another major downstream effector of EGFR. Navas et al. reported that EGFR positively regulates ERK phosphorylation in pancreatic cancer cells [11], which is consistent with our EGFR knockdown results. In contrast to decreased EGFR levels and activity, pERK levels were increased in a dose-dependent manner after $\mathrm{CuB}$ treatment for $24 \mathrm{~h}$ in BxPC-3 and HPAC cells, suggesting that enhanced pERK levels may be independent of EGFR downregulation by $\mathrm{CuB}$. We also observed increased pAMPK $\alpha$ levels following $24 \mathrm{~h}$ of $\mathrm{CuB}$ treatment in a dose-dependent manner. In particular, ERK and AMPK $\alpha$ showed synchronous changes in phosphorylation levels over time. Blocking AMPK function with an AMPK inhibitor or AMPK knockdown reversed the stimulatory effect of $\mathrm{CuB}$ on ERK activity. These findings reveal that CuB-induced ERK phosphorylation is dependent on activation of AMPK. Several studies have explored cross-talk between AMPK and ERK signaling, but the findings have been contradictory. Consistent with our results, two AMPK activators increased ERK activity in melanoma cells by inducing degradation of dual-specific phosphatase (DUSP) 6 [33]. A recent report [32] showed

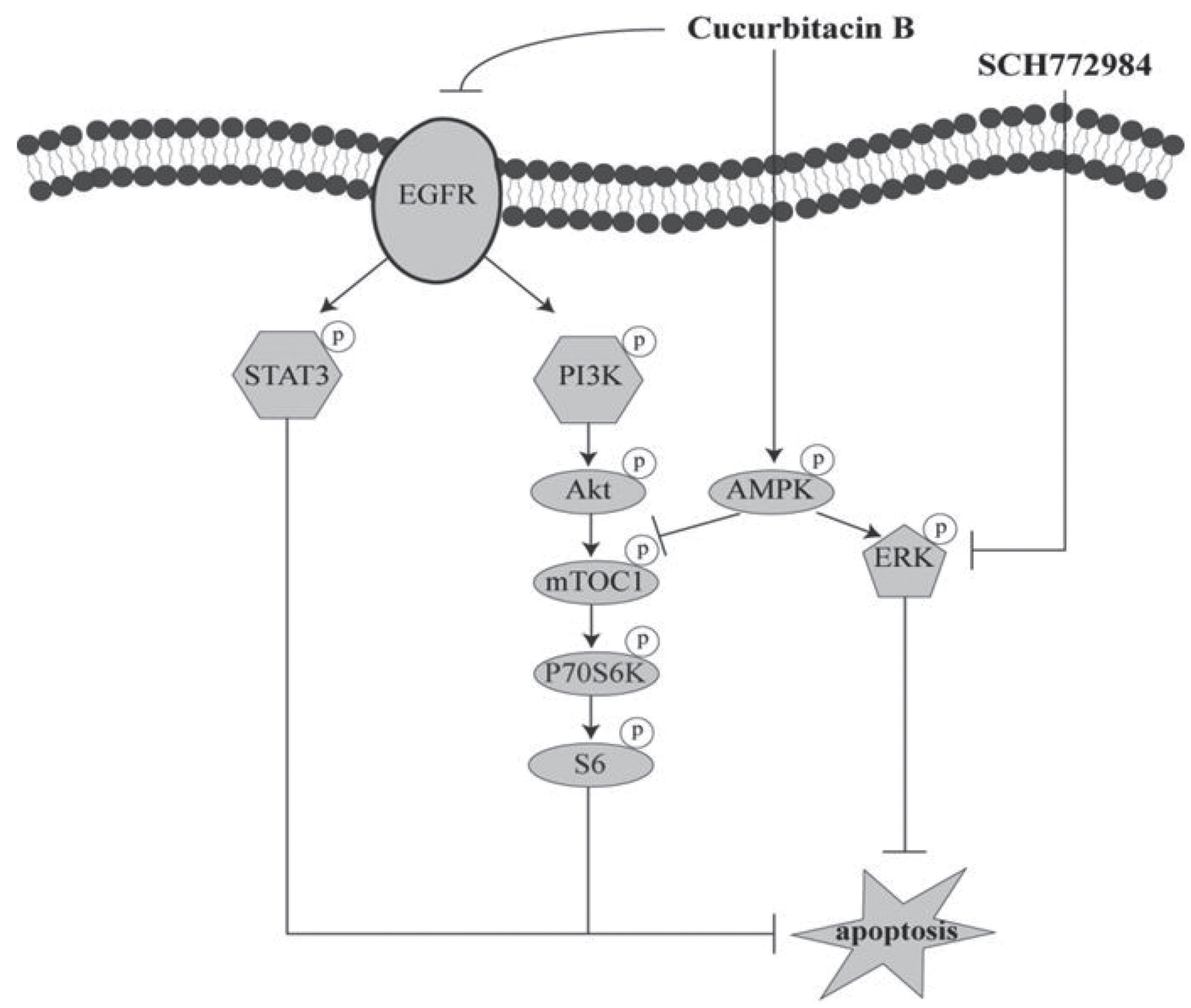

Figure 8: Proposed model of synergistic anti-pancreatic cancer activities of CuB and SCH772984. CuB suppresses EGFR levels, activity and downstream PI3K/Akt/mTOR and STAT3 signaling, but enhances ERK activity via AMPK activation, which inactivates the canonical apoptosis pathway. Addition of SCH772984 reverses ERK phosphorylation induced by CuB, thereby resulting in apoptosis. 
that 2-deoxyglucose suppressed ERK phosphorylation by LKB1/AMPK signaling. Regulation of ERK signaling by AMPK is highly complex and additional studies are needed to explain the precise mechanisms that link the two signaling pathways.

ERK is persistently activated in pancreatic cancer and plays crucial roles in tumorigenesis, cell proliferation and inhibition of apoptosis $[29,40]$. Thus, ERK inhibition by MEK/ERK inhibitors is an attractive therapeutic strategy in treating pancreatic cancer. Early trials with MEK inhibitors showed clinical activity, but their efficacy was mostly limited by toxic side effects, such as skin rash and visual disturbances [41]. EGFR or STAT3 feedback activation in response to MEK inhibitors was also shown to limit efficacy in pancreatic cancer cells $[12,42]$. Combination therapy with MEK and STAT3/EGFR inhibitors has been demonstrated to exert significant anti-pancreatic cancer efficacy $[12,42]$. Interestingly, our results showed a decrease in EGFR, STAT3, Akt and S6 activities and an increase in ERK activity in $2 \mathrm{CuB}$-treated pancreatic cancer cell lines. We deduce that the combination treatment with $\mathrm{CuB}$ and an ERK inhibitor against pancreatic cancer may be more effective than single drug treatment due to complementary effects on STAT3, ERK and EGFR activities. While combined treatment with $\mathrm{CuB}$ and $\mathrm{SCH} 772984$ showed synergistic growth inhibitory effects in 5 pancreatic cancer cells, an antagonistic effect was observed in normal pancreatic ductal epithelial cells, indicating that combined anti-pancreatic cancer therapy may be effective and safe. Moreover, combination treatment with $\mathrm{CuB}$ and SCH772984 significantly promoted pancreatic cancer cell apoptosis by simultaneously suppressing EGFR, STAT3, ERK, Akt and S6 activities, followed by an increase in the pro-apoptotic protein Bim and a decrease in antiapoptotic proteins $\mathrm{Mcl}-1, \mathrm{Bcl}-2, \mathrm{Bcl}-\mathrm{xl}$ and survivin. Importantly, synergistic antitumor reactions between $\mathrm{CuB}$ and SCH772984 were also observed in HPAC xenograft mice. These results are in accordance with a previous report, indicating that successful treatment of pancreatic cancer may require compound inhibition of at least 4 distinct signaling cascades, including those driven by KRAS, EGFR, PI3K and STAT3 [11].

In conclusion, $\mathrm{CuB}$ treatment had a strong growth inhibitory effect in pancreatic cancer cells by decreasing EGFR levels and downstream signaling of PI3K/Akt/ mTOR and STAT3. However, CuB increases ERK activity by activating AMPK signaling. $\mathrm{CuB}$ synergizes with SCH772984 to cause growth inhibition and apoptosis of pancreatic cancer cells in vitro and in vivo. This combination treatment is associated with complementary inhibition of EGFR, STAT3, ERK and PI3K/Akt/mTOR signaling, concomitant with an increase in Bim and a decrease in Mcl-1, Bcl-2, Bcl-xl and survivin. These data suggest that the activated AMPK-ERK pathway may contribute to resistance of pancreatic cancer cells to $\mathrm{CuB}$.

\section{MATERIALS AND METHODS}

\section{Drug}

Cucurbitacin B was purchased from the National Institute for the Control of Pharmaceutical and Biological Products (Beijing, China), with a purity of $99.63 \%$. SCH772984 was purchased from Ablome, USA. Compound $\mathrm{C}$ was purchased from Selleck Chemicals (Houston, TX).

\section{Cell culture}

Human pancreatic cancer cell lines, ASPC-1, BxPC3, CFPAC-1, HPAC and MiaPaCa-2, and the human normal pancreatic ductal epithelial cell line HPDE6-C7 were purchased from American Type Culture Collection (ATCC, Manassas, VA, USA) and cultured as previously described [43, 44]. Cell lines were tested for the presence of mycoplasma on a monthly basis using the PCR method described by Uphoff and Drexler [45]. Images are shown in Supplementary Figure 3.

\section{Cell viability assay}

Effects of cucurbitacin B and SCH772984 alone or in combination on pancreatic cancer cell growth were measured using the MTT (3-[4,5-dimethylthiazol-2-yl]2,5-diphenyltetrazolium-bromide, Sigma-Aldrich, St. Louis, MO, USA) reduction assay as previously described [46]. $\mathrm{IC}_{50}$ values were calculated as drug concentrations necessary to inhibit $50 \%$ of growth compared to untreated control cells. The extent and direction of $\mathrm{CuB}$ and SCH772984 cytotoxic interactions were determined by standard isobologram analyses and by evaluating combination index (CI) values, which were calculated using CompuSyn software (ComboSyn, Inc, Paramus, NJ, USA) where $\mathrm{CI}<1, \mathrm{CI}=1$, and $\mathrm{CI}>1$ indicate synergistic, additive, and antagonistic effects, respectively, as previously described [46-48].

\section{Cell death and cell cycle progression}

Cell death was determined by trypan blue exclusion. Cell cycle distribution was determined by PI staining followed by flow cytometry as previously described [48]. Dead cells were also recorded as $\mathrm{PI}^{+}$events (Sub-G1 population).

\section{LDH release assay}

Culture medium was collected and LDH activity was assessed using an LDH cytotoxicity assay kit (Nanjing Jiancheng Bioengineering Institute, China) according to the manufacturer's protocol. LDH activity was quantified by measuring absorbance at $450 \mathrm{~nm}$ with 
a microplate reader (Biotek, USA). LDH release $(\%)=$ $\left[\mathrm{OD}_{450}\right.$ (sample)-OD ${ }_{450}$ (low control)/OD ${ }_{450}$ (high control) $-\mathrm{OD}_{450}($ low control)] $\times 100$.

\section{Annexin V/PI staining}

BxPC-3 and HPAC cells were treated with $\mathrm{CuB}$ and SCH772984 alone or in combination and subjected to flow cytometry analysis to determine drug-induced cell death using an annexin V-fluorescein isothiocyanate (FITC)/ propidium iodide (PI) apoptosis kit (Beckman Coulter, Brea, CA, USA) and a FACS Calibur flow cytometer (Becton Dickinson, San Jose, CA, USA) as previously described $[46,49]$.

\section{Western blotting analysis}

Western blotting was performed using polyvinylidene difluoride (PVDF) membranes (Thermo Fisher Inc., Rockford, IL, USA) and immunoblotted with anti-EGFR, -pEGFR (Y1173), -STAT3, -pSTAT3(Y705), -AKT (Abcam, Cambridge, MA, USA), -PARP, -ERK, -pERK (T202/204), -pS6 (S240/244), -CDK1, -pCDK1(Y15), -CyclinB1, -Bcl-2, -Bcl-xl, -Mcl1, -Survivin, -Bim, -AMPK $\alpha$ and -pAMPK $\alpha$ (T172) (Cell Signaling Technology, Danvers, MA, USA), -pAKT(T308), -pAKT(S473) (Affinity Biologicals, USA), or $\beta$-actin antibodies (Sigma-Aldrich) as previously described [49]. Immunoreactive proteins were visualized using the Odyssey Infrared Imaging System (Li-Cor) as described by the manufacturer.

\section{shRNA knockdown of EGFR}

pMD-VSV-G and delta 8.2 plasmids were gifts from Dr. Dong at Tulane University. Plasmid maps are shown in Supplementary Figure 2. EGFR and non-target control lentiviral vectors were purchased from Sigma-Aldrich. Transfection was performed using Lipofectamine 3000 reagent (Invitrogen, USA) according to the manufacturer's instructions. Briefly, a lentivirus vector, pMD-VSV-G, and delta 8.2 were cotransfected into TLA-HEK293T cells, and the culture medium was harvested $72 \mathrm{~h}$ post-transfection. BxPC-3 and HPAC cells were transduced by adding virus supernatant and polybrene (Sigma-Aldrich) for $3 \mathrm{~h}$. Cells were harvested 5 days after lentiviral infection and used for subsequent analysis.

\section{CRISPR knockdown of AMPKa}

The lentiCRISPRv2 plasmid was derived from Feng Zhang (Addgene plasmid \#52961 [50]). Guide RNAs (gRNAs) were designed using the CRISPR design tool (http://crispr.mit.edu). Non-target control (NTC) and AMPK $\alpha$ vectors were generated using Feng Zhang's protocol, which is available on the Addgene website (www. addgene.org). Lentivirus production and transduction were performed as described, except that psPAX2 (from Didier Trono, Addgene plasmid \#12260) was used instead of delta 8.2 [51]. The following gRNAs were used: AMPK $\alpha$, 5'-AGTGCCATGCATATTCCCCC-3', NTC, 5'-GCACTACCAGAGCTAACTCA-3'.

\section{Establishment of a mouse pancreatic cancer xenograft model}

Female BALB/c nude mice (18-22 g) were purchased from Vital River Laboratories (Beijing, China). The animal study was conducted following internationally recognized guidelines and was approved by the Animal Research Committee of Norman Bethune College of Medicine, Jilin University. The HPAC xenograft model was generated as previously described [43]. When the xenografts reached a volume of $106.9 \pm 13.4 \mathrm{~mm}^{3}$, mice were randomized into 4 groups ( 5 animals per group, with mean tumor volumes of $104.1 \pm 7.7,105.7 \pm 7.3,104.7$ \pm 8.3 and $115.2 \pm 9.0 \mathrm{~mm}^{3}$ for the vehicle control, $\mathrm{CuB}$, $\mathrm{SCH} 772984$, and combination group, respectively) and treated with (i) vehicle control, (ii) $0.5 \mathrm{mg} / \mathrm{kg} \mathrm{CuB}$ three times per week by intraperitoneal injection, (iii) $25 \mathrm{mg} / \mathrm{kg}$ SCH772984 daily by intraperitoneal injection, or (iv) 0.5 $\mathrm{mg} / \mathrm{kg} \mathrm{CuB}$ three times a week by intraperitoneal injection and $25 \mathrm{mg} / \mathrm{kg} \mathrm{SCH} 772984$ daily by intraperitoneal injection for 4 weeks. Tumor diameters were measured with a caliper daily. Mice were sacrificed after tumors in the control group reached $1000 \mathrm{~mm}^{3}$ by cervical vertebra dislocation. Tumor volume was calculated according to the following formula: $\mathrm{m}_{1}^{2} \times \mathrm{m}_{2} \times 0.5236\left(\mathrm{~m}_{1}\right.$ : short diameter; $\mathrm{m}_{2}$ : long diameter $)$. Tumor growth inhibition was calculated using the equation $100 \% \times \mathrm{T} / \mathrm{C}$, where $\mathrm{C}=$ final mean tumor volume - initial tumor volume for the control and $\mathrm{T}=$ final mean tumor volume - initial tumor volume for the treated groups.

\section{Hematoxylin and eosin, immunohistochemical and TUNEL staining}

On day 28, mice were sacrificed and tumors from 5 mice in each treatment group were excised for hematoxylin and eosin (HE), proliferating cell nuclear antigen (PCNA) immunohistochemical and TUNEL staining. Immunohistochemical staining was analyzed using Motic Images Advanced 3.2 and expressed as the mean optical density (MOD). Five fields of vision without any overlap in each section were selected randomly and photographed at 200 magnification. Areas to measure were first detected using software, and integrated optical density of the target stain region was subsequently determined. The MOD from each slide reflected positive PCNA or TUNNEL expression. A higher MOD indicates increased positive expression. 


\section{Statistical analysis}

Data are expressed as the mean \pm standard deviation of three experiments. Differences in the sample means between test groups and control groups were analyzed using the pair-wise two-sample $t$-test. Statistical analyses were performed with GraphPad Prism 5.0. $P$ values less than 0.05 were considered significant and labeled as ${ }^{*} p<$ $0.05,{ }^{* *} p<0.01$, or ${ }^{* * *} p<0.001$.

\section{Abbreviations}

PI: propidium iodide, H\&E: hematoxylin and eosin, ip: intraperitoneal injection, T: mean treated tumor volume; C: control treated tumor volume.

\section{Author contributions}

JZ, TZ, LM, and LM performed the in vitro and in vivo studies. LZ and YG participated in the design and coordination of the study. All authors read and approved the final manuscript.

\section{CONFLICTS OF INTEREST}

The authors declare no competing financial interests.

\section{FUNDING}

This project was supported by the National Natural Science Foundation of China (No.81673510).

\section{REFERENCES}

1. Siegel R, Desantis C, Jemal A. Colorectal cancer statistics, 2014. CA Cancer J Clin. 2014; 64:104-117.

2. Vulfovich M, Rocha-Lima C. Novel advances in pancreatic cancer treatment. Expert Rev Anticancer Ther. 2008; 8:9931002 .

3. Xiong HQ, Abbruzzese JL. Epidermal growth factor receptor-targeted therapy for pancreatic cancer. Semin Oncol. 2002; 29:31-37.

4. Henson ES, Gibson SB. Surviving cell death through epidermal growth factor (EGF) signal transduction pathways: implications for cancer therapy. Cell Signal. 2006; 18:2089-2097.

5. Haura EB, Cress WD, Chellappan S, Zheng Z, Bepler G. Antiapoptotic signaling pathways in non-small-cell lung cancer: biology and therapeutic strategies. Clin Lung Cancer. 2004; 6:113-122.

6. Dong M, Nio Y, Guo KJ, Tamura K, Tian YL, Dong YT. Epidermal growth factor and its receptor as prognostic indicators in Chinese patients with pancreatic cancer. Anticancer Res. 1998; 18:4613-4619.
7. Oliveira-Cunha M, Newman WG, Siriwardena AK. Epidermal growth factor receptor in pancreatic cancer. Cancer. 2011; 3:1513-1526.

8. Valsecchi ME, McDonald M, Brody JR, Hyslop T, Freydin B, Yeo CJ, Solomides C, Peiper SC, Witkiewicz AK. Epidermal growth factor receptor and insulinlike growth factor 1 receptor expression predict poor survival in pancreatic ductal adenocarcinoma. Cancer. 2012; 118:3484-3493.

9. Faller BA, Burtness B. Treatment of pancreatic cancer with epidermal growth factor receptor-targeted therapy. Biologics. 2009; 3:419-428.

10. Slebos RJ, Hoppin JA, Tolbert PE, Holly EA, Brock JW, Zhang RH, Bracci PM, Foley J, Stockton P, McGregor LM, Flake GP, Taylor JA. k-Ras and p53 in pancreatic cancer: association with medical history, histopathology and environmental exposures in a population-based study. Cancer Epidemiol Biomarkers Prev. 2000; 9:1223-1232.

11. Navas C, Hernandez-Porras I, Schuhmacher AJ, Sibilia M, Guerra C, Barbacid M. EGF receptor signaling is essential for $\mathrm{k}$-Ras oncogene-driven pancreatic ductal adenocarcinoma. Cancer cell. 2012; 22:318-330.

12. Zhao C, Xiao H, Wu X, Li C, Liang G, Yang S, Lin J. Rational combination of MEK inhibitor and the STAT3 pathway modulator for the therapy in K-Ras mutated pancreatic and colon cancer cells. Oncotarget. 2015; 6:14472-14487. https://doi.org/10.18632/oncotarget.3991.

13. Soares HP, Ming M, Mellon M, Young SH, Han L, SinnetSmith J, Rozengurt E. Dual PI3K/mTOR inhibitors induce rapid overactivation of the MEK/ERK pathway in human pancreatic cancer cells through suppression of mTORC2. Mol Cancer Ther. 2015; 14:1014-1023.

14. Walters DM, Lindberg JM, Adair SJ, Newhook TE, Cowan CR, Stokes JB, Borgman CA, Stelow EB, Lowrey BT, Chopivsky ME, Gilmer TM, Parsons JT, Bauer TW. Inhibition of the growth of patient-derived pancreatic cancer xenografts with the MEK inhibitor trametinib is augmented by combined treatment with the epidermal growth factor receptor/HER2 inhibitor lapatinib. Neoplasia. 2013; 15:143-155.

15. Diep CH, Munoz RM, Choudhary A, Von Hoff DD, Han H. Synergistic effect between erlotinib and MEK inhibitors in KRAS wild-type human pancreatic cancer cells. Clin Cancer Res. 2011; 17:2744-2756.

16. Jimeno A, Rubio-Viqueira B, Amador ML, Grunwald V, Maitra A, Iacobuzio-Donahue C, Hidalgo M. Dual mitogenactivated protein kinase and epidermal growth factor receptor inhibition in biliary and pancreatic cancer. Mol Cancer Ther. 2007; 6:1079-1088.

17. Chen JC, Chiu MH, Nie RL, Cordell GA, Qiu SX. Cucurbitacins and cucurbitane glycosides: structures and biological activities. Nat Prod Rep. 2005; 22:386-399.

18. Guo J, Wu G, Bao J, Hao W, Lu J, Chen X. Cucurbitacin B induced ATM-mediated DNA damage causes G2/M cell cycle arrest in a ROS-dependent manner. PloS one. 2014; 9:e88140. 
19. Kausar H, Munagala R, Bansal SS, Aqil F, Vadhanam MV, Gupta RC. Cucurbitacin B potently suppresses non-smallcell lung cancer growth: identification of intracellular thiols as critical targets. Cancer Lett. 2013; 332:35-45.

20. Duangmano S, Dakeng S, Jiratchariyakul W, Suksamrarn A, Smith DR, Patmasiriwat P. Antiproliferative effects of cucurbitacin $\mathrm{B}$ in breast cancer cells: down-regulation of the c-Myc/hTERT/telomerase pathway and obstruction of the cell cycle. Int J Mol. 2010; 11:5323-5338.

21. Zhang M, Sun C, Shan X, Yang X, Li-Ling J, Deng Y. Inhibition of pancreatic cancer cell growth by cucurbitacin $\mathrm{B}$ through modulation of signal transducer and activator of transcription 3 signaling. Pancreas. 2010; 39:923-929.

22. Thoennissen NH, Iwanski GB, Doan NB, Okamoto R, Lin P, Abbassi S, Song JH, Yin D, Toh M, Xie WD, Said JW, Koeffler HP. Cucurbitacin B induces apoptosis by inhibition of the JAK/STAT pathway and potentiates antiproliferative effects of gemcitabine on pancreatic cancer cells. Cancer Res. 2009; 69:5876-5884.

23. Iwanski GB, Lee DH, En-Gal S, Doan NB, Castor B, Vogt M, Toh M, Bokemeyer C, Said JW, Thoennissen NH, Koeffler HP. Cucurbitacin B, a novel in vivo potentiator of gemcitabine with low toxicity in the treatment of pancreatic cancer. Br J Pharmacol. 2010; 160:998-1007.

24. Seo CR, Yang DK, Song NJ, Yun UJ, Gwon AR, Jo DG, Cho JY, Yoon K, Ahn JY, Nho CW, Park WJ, Yang SY, Park KW. Cucurbitacin B and cucurbitacin I suppress adipocyte differentiation through inhibition of STAT3 signaling. Food Chem Toxicol. 2014; 64:217-224.

25. Kim SR, Seo HS, Choi HS, Cho SG, Kim YK, Hong EH, Shin YC, Ko SG. Trichosanthes kirilowii ethanol extract and cucurbitacin D inhibit cell growth and induce apoptosis through inhibition of STAT3 activity in breast cancer cells. Evid Based Complement Alternat Med. 2013; 2013:975350.

26. Blaskovich MA, Sun J, Cantor A, Turkson J, Jove R, Sebti SM. Discovery of JSI-124 (cucurbitacin I), a selective Janus kinase/signal transducer and activator of transcription 3 signaling pathway inhibitor with potent antitumor activity against human and murine cancer cells in mice. Cancer Res. 2003; 63:1270-1279.

27. Gupta P, Srivastava SK. Inhibition of integrin-HER2 signaling by cucurbitacin B leads to in vitro and in vivo breast tumor growth suppression. Oncotarget. 2014; 5:1812-1828. https://doi.org/10.18632/oncotarget.1773.

28. Silva IT, Carvalho A, Lang KL, Dudek SE, Masemann D, Duran FJ, Caro MS, Rapp UR, Wixler V, Schenkel $\mathrm{EP}$, Simoes CM, Ludwig S. In vitro and in vivo antitumor activity of a novel semisynthetic derivative of cucurbitacin B. PloS one. 2015; 10:e0117794.

29. Roskoski R Jr. ERK1/2 MAP kinases: structure, function, and regulation. Pharmacol Res. 2012; 66:105-143.

30. Hayes TK, Neel NF, Hu C, Gautam P, Chenard M, Long B, Aziz M, Kassner M, Bryant KL, Pierobon M, Marayati
R, Kher S, George SD, et al. Long-term ERK inhibition in KRAS-mutant pancreatic cancer is associated with MYC degradation and senescence-like growth suppression. Cancer cell. 2016; 29:75-89.

31. Morris EJ, Jha S, Restaino CR, Dayananth P, Zhu H, Cooper A, Carr D, Deng Y, Jin W, Black S, Long B, Liu J, Dinunzio E, et al. Discovery of a novel ERK inhibitor with activity in models of acquired resistance to BRAF and MEK inhibitors. Cancer Discov. 2013; 3:742-750.

32. Sun L, Liu X, Fu H, Zhou W, Zhong D. 2-Deoxyglucose suppresses ERK phosphorylation in LKB1 and Ras wildtype non-small cell lung cancer cells. PloS one. 2016; 11:e0168793.

33. Martin MJ, Hayward R, Viros A, Marais R. Metformin accelerates the growth of BRAF V600E-driven melanoma by upregulating VEGF-A. Cancer Discov. 2012; 2:344-355.

34. Shen CH, Yuan P, Perez-Lorenzo R, Zhang Y, Lee SX, Ou Y, Asara JM, Cantley LC, Zheng B. Phosphorylation of BRAF by AMPK impairs BRAF-KSR1 association and cell proliferation. Mol Cell. 2013; 52:161-172.

35. Vincent A, Herman J, Schulick R, Hruban RH, Goggins M. Pancreatic cancer. Lancet. 2011; 378:607-620.

36. Hezel AF, Kimmelman AC, Stanger BZ, Bardeesy N, Depinho RA. Genetics and biology of pancreatic ductal adenocarcinoma. Genes Dev. 2006; 20:1218-1249.

37. Hingorani SR, Wang L, Multani AS, Combs C, Deramaudt TB, Hruban RH, Rustgi AK, Chang S, Tuveson DA. Trp53R172H and KrasG12D cooperate to promote chromosomal instability and widely metastatic pancreatic ductal adenocarcinoma in mice. Cancer cell. 2005; 7:469-483.

38. Brembeck FH, Schreiber FS, Deramaudt TB, Craig L, Rhoades B, Swain G, Grippo P, Stoffers DA, Silberg DG, Rustgi AK. The mutant K-ras oncogene causes pancreatic periductal lymphocytic infiltration and gastric mucous neck cell hyperplasia in transgenic mice. Cancer Res. 2003; 63:2005-2009.

39. Fujita H, Ohuchida K, Mizumoto K, Itaba S, Ito T, Nakata K, Yu J, Kayashima T, Hayashi A, Souzaki R, Tajiri T, Onimaru M, Manabe T, et al. High EGFR mRNA expression is a prognostic factor for reduced survival in pancreatic cancer after gemcitabine-based adjuvant chemotherapy. Int J Oncology. $2011 ; 38$.

40. Tyagi N, Bhardwaj A, Singh AP, McClellan S, Carter JE, Singh S. p-21 activated kinase 4 promotes proliferation and survival of pancreatic cancer cells through AKTand ERK-dependent activation of NF-kappaB pathway. Oncotarget. 2014; 5:8778-8789. https://doi.org/10.18632/ oncotarget.2398.

41. Samatar AA, Poulikakos PI. Targeting RAS-ERK signalling in cancer: promises and challenges. Rev Drug Discov. 2014; 13:928-942.

42. Lindberg JM, Newhook TE, Adair SJ, Walters DM, Kim AJ, Stelow EB, Parsons JT, Bauer TW. Co-treatment with panitumumab and trastuzumab augments response to the 
MEK inhibitor trametinib in a patient-derived xenograft model of pancreatic cancer. Neoplasia. 2014; 16:562-571.

43. Chen S, Wang G, Niu X, Zhao J, Tan W, Wang H, Zhao L, Ge Y. Combination of AZD2281 (Olaparib) and GX15-070 (Obatoclax) results in synergistic antitumor activities in preclinical models of pancreatic cancer. Cancer Lett. 2014; 348:20-28.

44. Cheng X, Wang B, Jin Z, Ma D, Yang W, Zhao R, Jing X, Shen B, Peng C, Qiu W. Pseudomonas aeruginosa-mannosesensitive hemagglutinin inhibits pancreatic cancer cell proliferation and induces apoptosis via the EGFR pathway and caspase signaling. Oncotarget. 2016; 7:77916-77925.

45. Uphoff CC, Drexler HG. Detection of mycoplasma contaminations. Methods Mol Biol. 2005; 290:13-23.

46. Xie C, Edwards H, Xu X, Zhou H, Buck SA, Stout ML, Yu Q, Rubnitz JE, Matherly LH, Taub JW, Ge Y. Mechanisms of synergistic antileukemic interactions between valproic acid and cytarabine in pediatric acute myeloid leukemia. Clin Cancer Res. 2010; 16:5499-5510.

47. Chou TC. Theoretical basis, experimental design and computerized simulation of synergism and antagonism in drug combination studies. Pharmacol Rev. 2006; 58:621-681.
48. Wang G, He J, Zhao J, Yun W, Xie C, Taub JW, Azmi A, Mohammad RM, Dong Y, Kong W, Guo Y, Ge Y. Class I and class II histone deacetylases are potential therapeutic targets for treating pancreatic cancer. PloS one. 2012; 7:e52095.

49. Edwards H, Xie C, LaFiura KM, Dombkowski AA, Buck SA, Boerner JL, Taub JW, Matherly LH, Ge Y. RUNX1 regulates phosphoinositide 3-kinase/AKT pathway: role in chemotherapy sensitivity in acute megakaryocytic leukemia. Blood. 2009; 114:2744-2752.

50. Sanjana NE, Shalem O, Zhang F. Improved vectors and genome-wide libraries for CRISPR screening. Nat Methods. 2014; 11:783-784.

51. Niu X, Zhao J, Ma J, Xie C, Edwards H, Wang G, Caldwell JT, Xiang S, Zhang X, Chu R, Wang ZJ, Lin H, Taub JW, et al. Binding of released Bim to Mcl-1 is a mechanism of intrinsic resistance to ABT-199 which can be overcome by combination with daunorubicin or cytarabine in AML cells. Clin Cancer Res. 2016; 22:4440-4451. 